\section{Questión}

Periodismo / Comunicación ISSN 1669-6581
- Av. $44 \mathrm{~N}^{\circ} 676,1^{\circ}$ piso

CP 1900 - La Plata - Argentina

www.perio.unlp.edu.ar/question

Esto no es un mural

Luciano Montolivo y Felicitas Faur

DOI: https://doi.org/10.24215/16696581e340

\title{
Esto no es un mural
}

\section{This isn't a mural.}

Felicitas Faur: @fefaur

Lucho Montolivo: @lucho.montolivo

Taller Galería: @veranoal2020

Hola, somos Lucho Montolivo y Fefaur, de veranoal2020, y como ustedes estamos encerrados. Verano es nuestro taller-galería, en él trabajamos y distintos organizamos eventos culturales. Estábamos pintando ahí justo cuando se declaró la cuarentena obligatoria. Tenemos días muy arriba y días muy abajo, y días que parecen ser una meseta que no va a terminar nunca, pero sobre todas las cosas, sentimos que estos días son de mucho aprendizaje. Ambos somos artistas independientes, que en la actualidad nos encontramos en La Plata. Nuestro trabajo consiste en ilustrar, desde flyers, tapa de discos, cuentos, hasta pintar murales y cuadros. Nuestro fuerte son los murales, y debido a este presente, no estaríamos pudiendo trabajar al aire libre, lo cual nos tiene un poco ansiosos y buscando constantemente nuevos proyectos y tejiendo redes para poder sobrevivir al aislamiento.

Ya es el día 40 y pico de esta cuarentena, y siento que no hice nada, pero sin embargo miro atrás unos días y hicimos un montón de cosas, creo que la cuarentena nos hizo percibir el tiempo de otra manera, apreciar los momentos. Miramos hacia atrás y antes de empezar con la cuarentena nos encontrábamos en Mendoza viajando y pintando y haciendo amigos, constantemente en movimiento de un lado para el otro, lo cual es hermoso. Pero sin embargo si hubiésemos mantenido ese movimiento constante, esa velocidad que se acrecienta día a día hubiese seguido, nunca hubiésemos parado y nos hubiésemos observado introspectivamente, 
hacia nosotros, nuestros sentimientos y nuestra imagen. Este mes y medio y los días que falten, creo que más allá de sentirnos en stand by, crecimos muchísimo a nivel laboral, técnica, etc. Obligadamente tuvimos que pensar en nosotros de una vez por todas y no dejar que nuestros deseos pasen por nuestro costado.

Fue gracioso que cuando se declaró el confinamiento la gente se saturó de actividades, de cosas para hacer, de cosas que nunca habían hecho, y llenase todos esos "vacíos", esa ansiedad generada por nosotros mismos y la velocidad inherente al presente y al momento en que vivimos, nosotros nos metimos en esa bola, y las primeras semanas estábamos haciendo cosas muy a pleno, produciendo sin parar. La segunda mitad de la cuarentena fue muy diferente, quizás más angustiosa, y con más recaídas, pero más conscientes de que el mundo cambió y las cosas cambiaron, por ende, nosotros debemos cambiar, entonces empezamos a apreciar más los detalles, el tiempo de los procesos, la charla, los silencios, no por eso se volvió más fácil pero seguro que es un buen aprendizaje.

\section{Videos:}

https://youtu.be/Vpcv7xmmRrU

https://youtu.be/gHkXIkm4y5E

\section{Imágenes:}




\section{(c) $\underset{\mathrm{BY}}{\mathrm{BY}(\mathrm{NC})(2 \mathrm{SA}}$}

Esta obra está bajo una Licencia Creative Commons

Atribución-NoComercial-Compartir Igual 4.0 Internacional

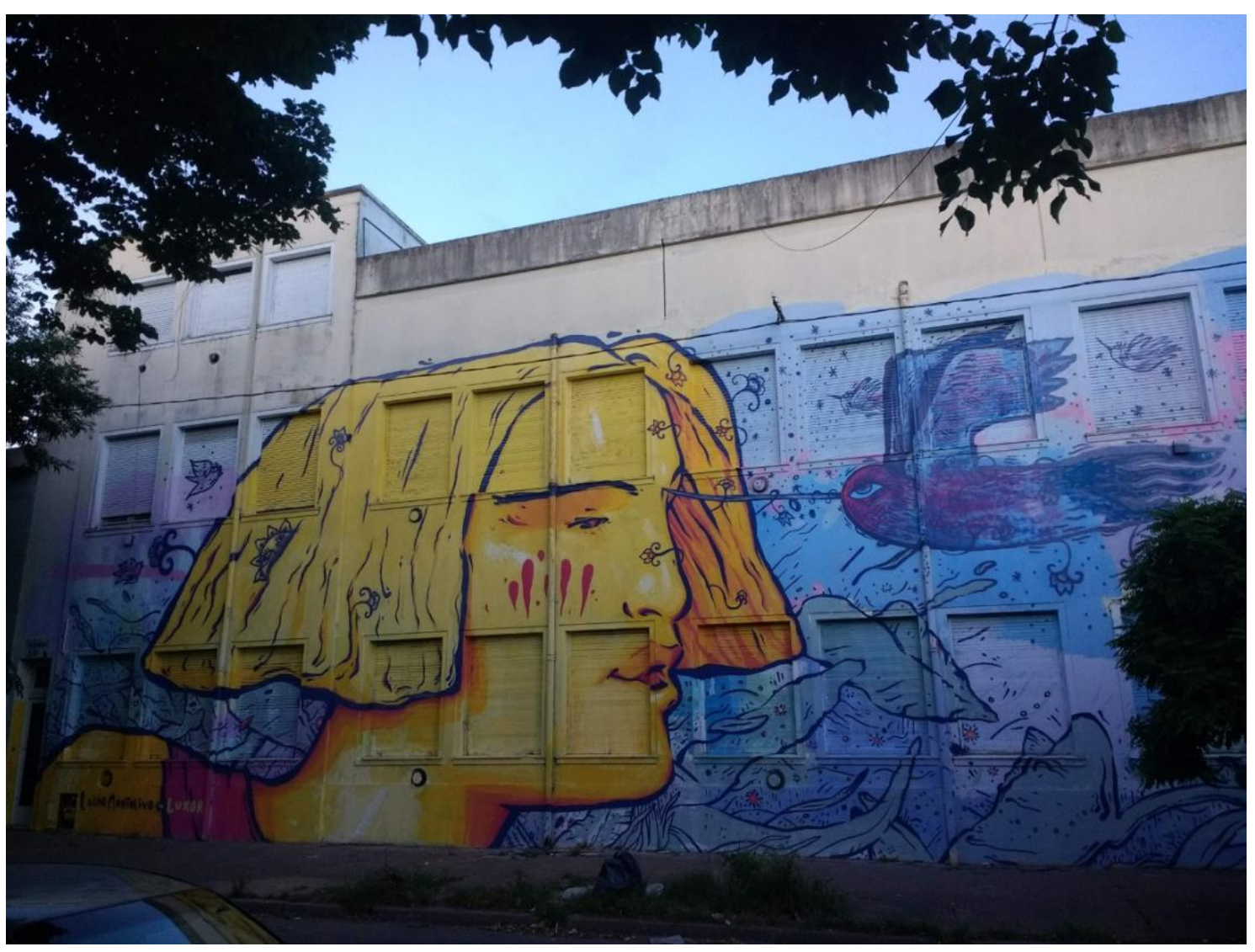




\section{(c) $\underset{\mathrm{BY} \text { NC SA }}{(\text { (1) }}$}

Esta obra está bajo una Licencia Creative Commons

Atribución-NoComercial-Compartir Igual 4.0 Internacional

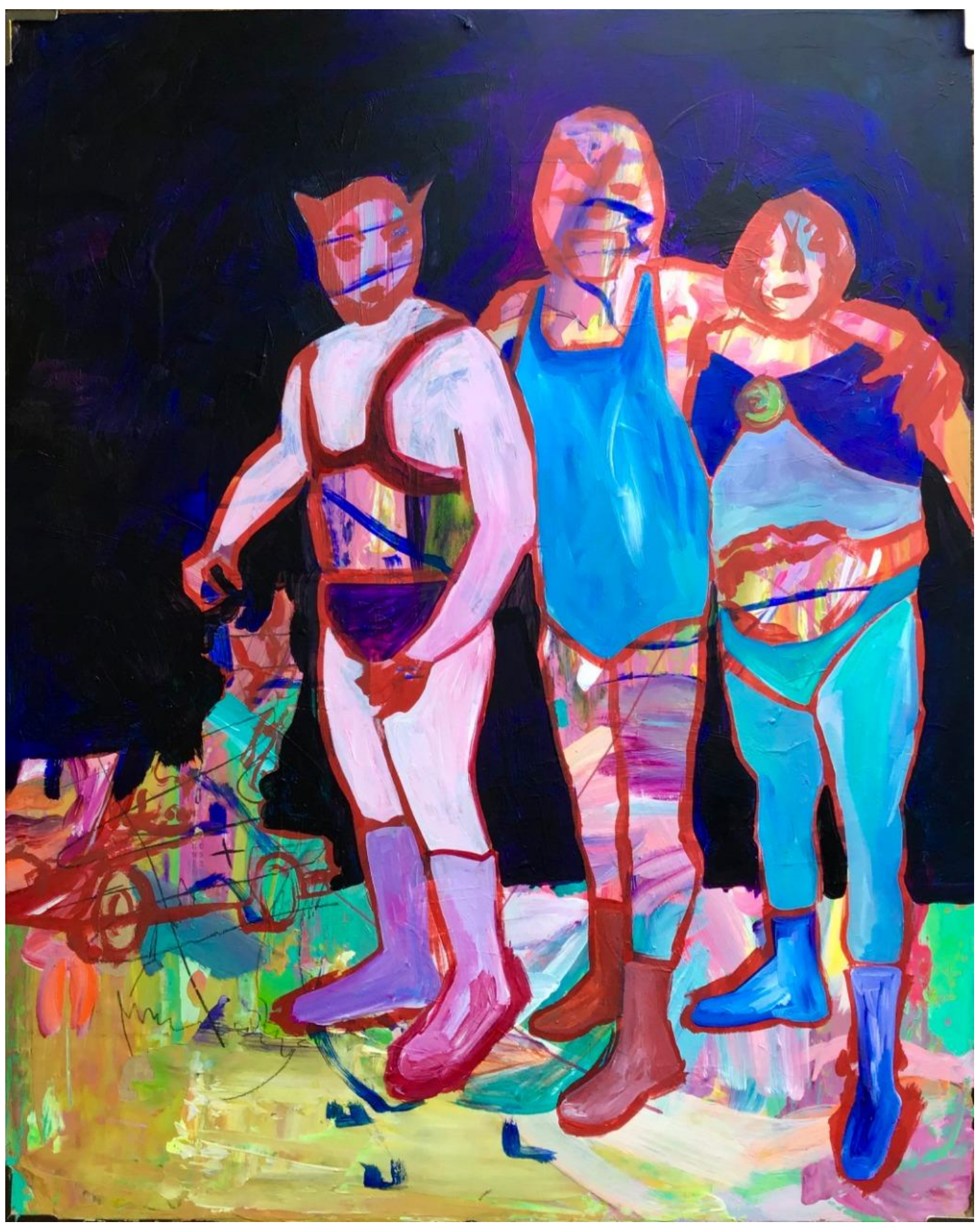

Question/Cuestión, Informe Especial Incidentes III, mayo 2020. ISSN 1669-6581

IICom (Instituto de Investigaciones en Comunicación)

Facultad de Periodismo y Comunicación Social

Universidad Nacional de La Plata 


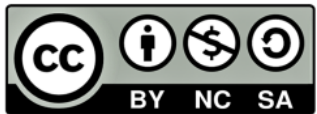

Esta obra está bajo una Licencia Creative Commons

Atribución-NoComercial-Compartir Igual 4.0 Internacional

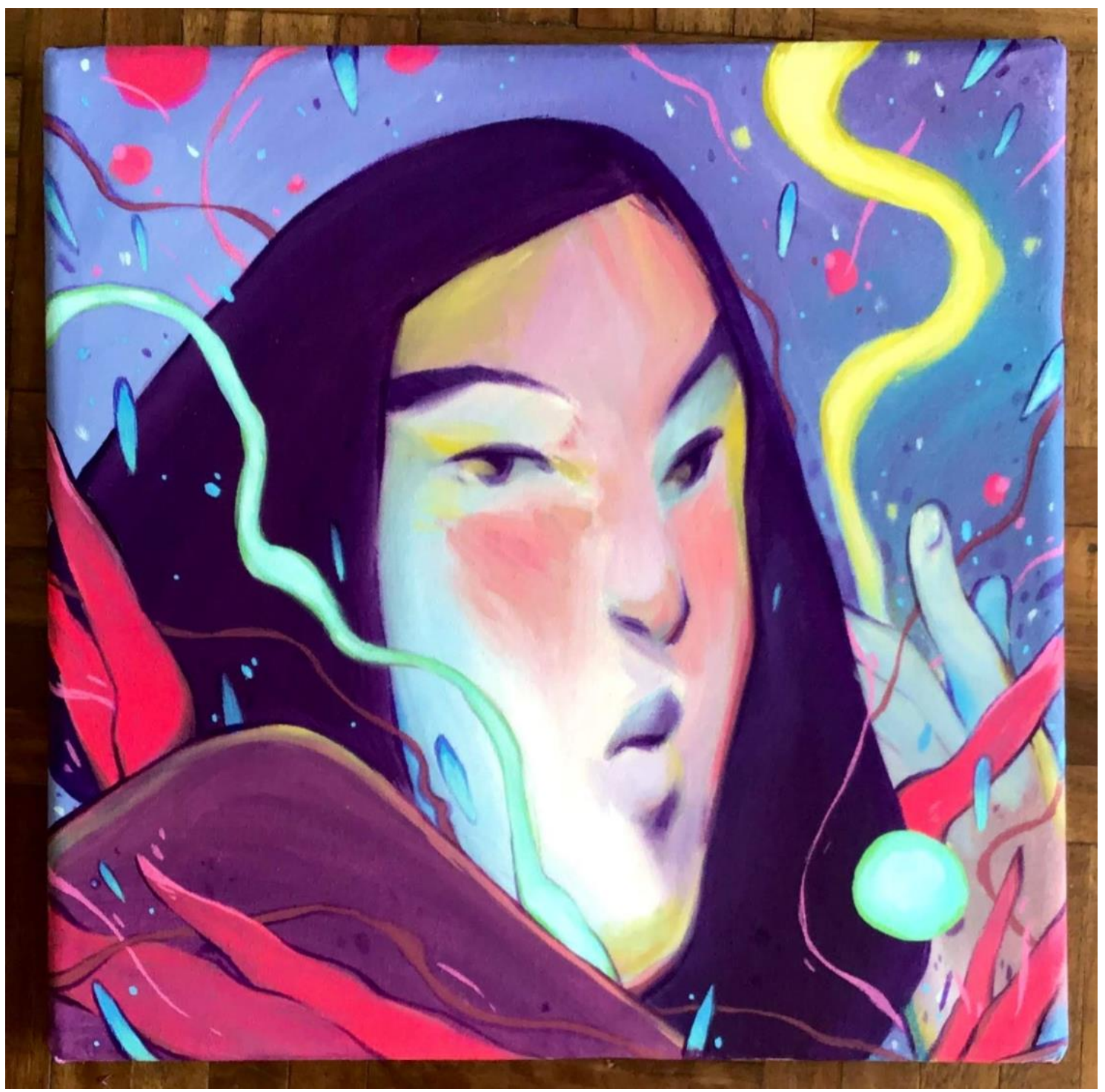




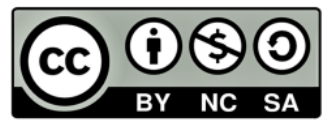

Esta obra está bajo una Licencia Creative Commons

Atribución-NoComercial-Compartir Igual 4.0 Internacional

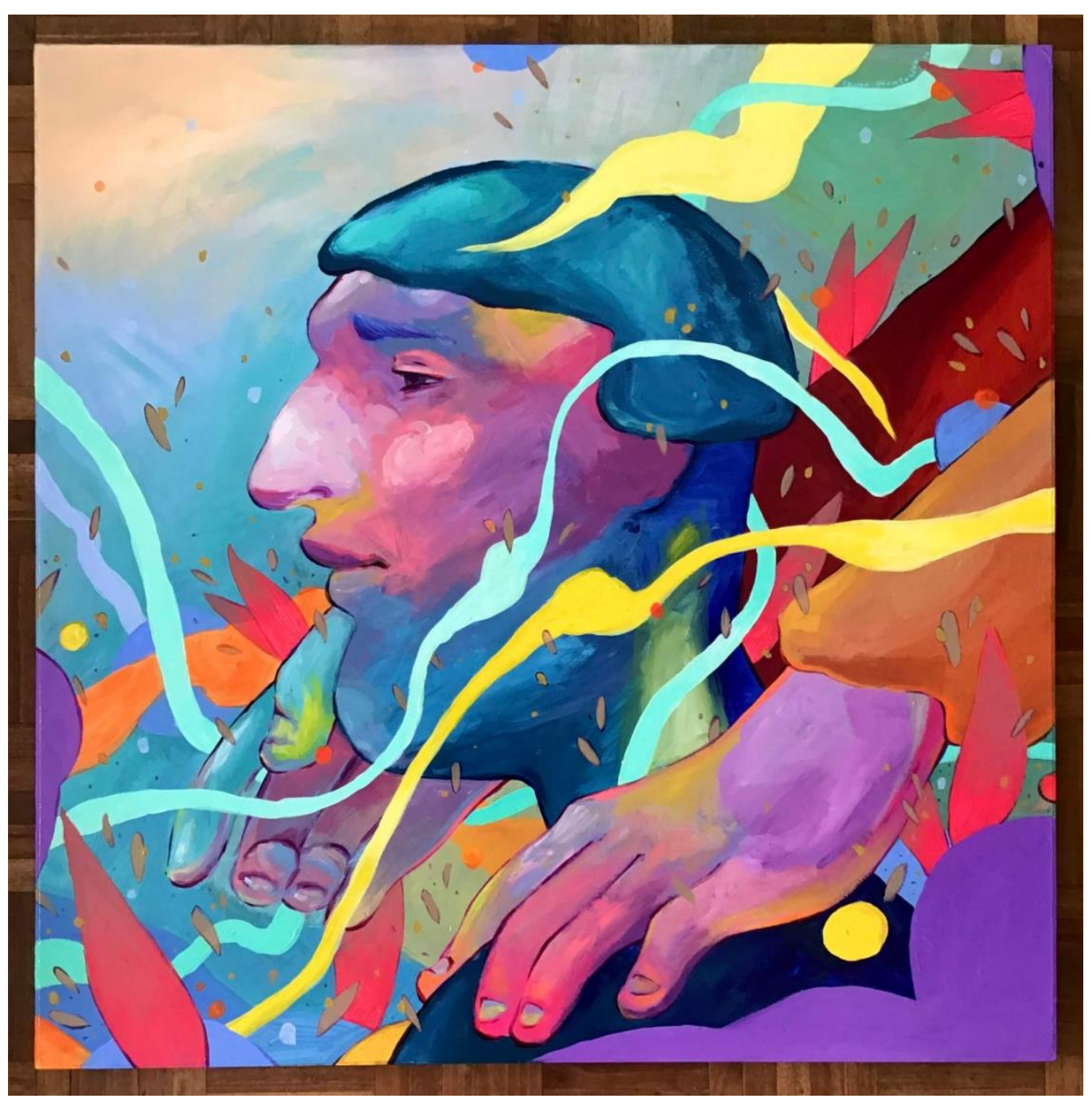




\section{(c) $\underset{\mathrm{BY} \text { NC SA }}{(\text { (1) }}$}

Esta obra está bajo una Licencia Creative Commons

Atribución-NoComercial-Compartir Igual 4.0 Internacional

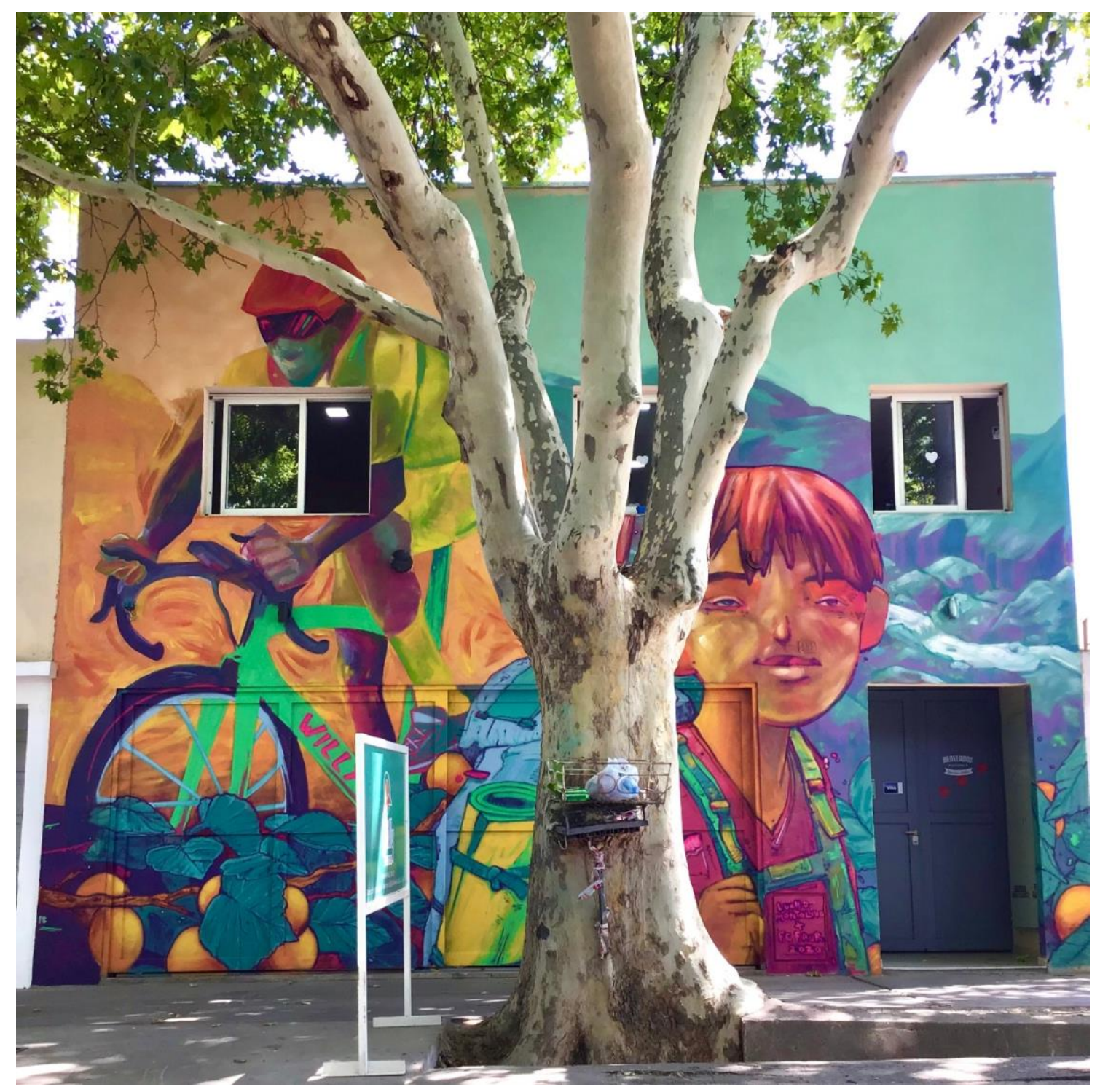




\section{(c) (1) (2)(2)}

Esta obra está bajo una Licencia Creative Commons

Atribución-NoComercial-Compartir Igual 4.0 Internacional

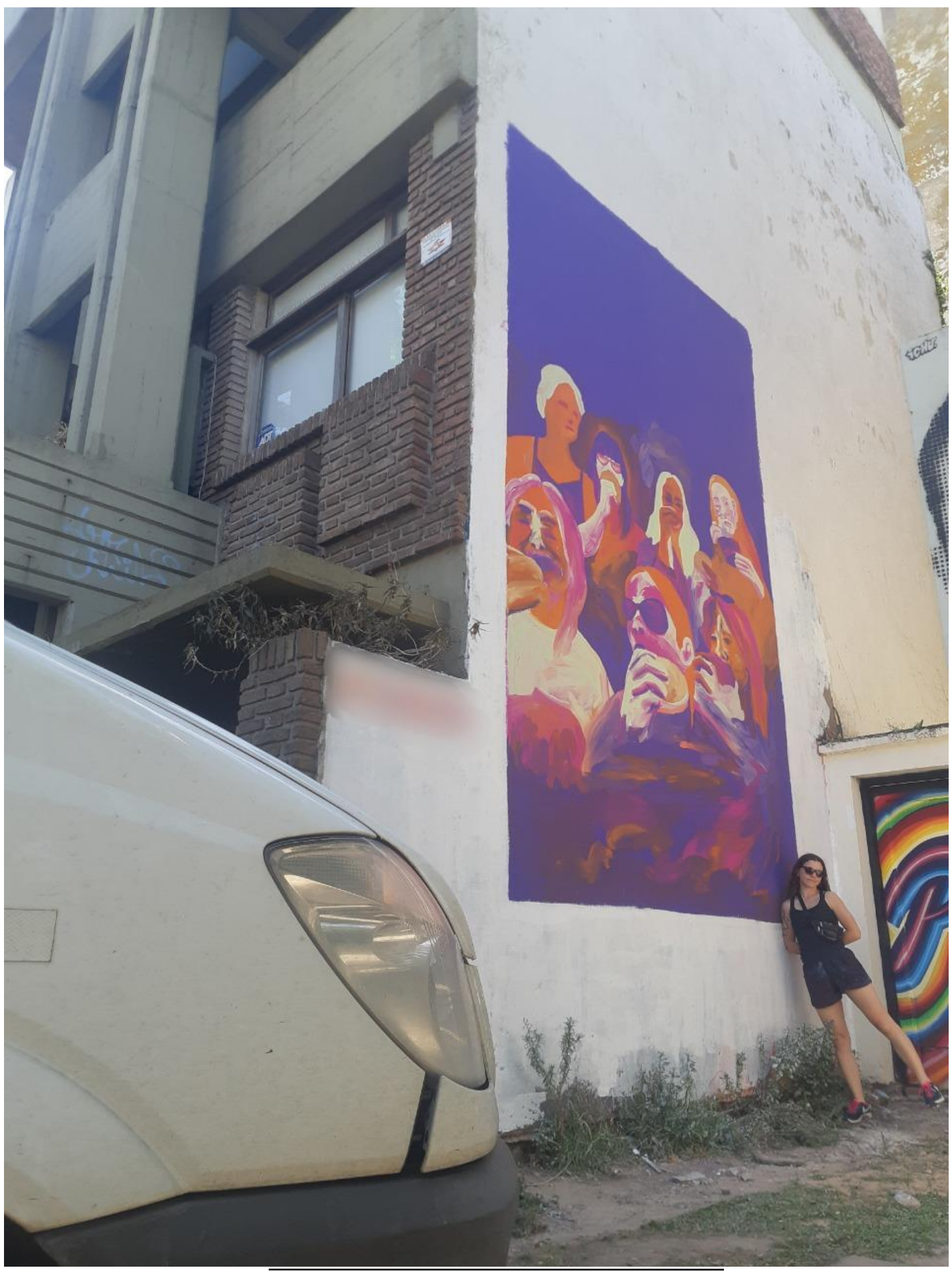

Question/Cuestión, Informe Especial Incidentes III, mayo 2020. ISSN 1669-6581

IICom (Instituto de Investigaciones en Comunicación)

Facultad de Periodismo y Comunicación Social

Universidad Nacional de La Plata 